\title{
Diálogos entre Ciência e Arte: Uma leitura a partir da obra de Remedios Varo para um Ensino sobre as Ciências
}

Taina de Araujo Carvalho ${ }^{1}$

Mestranda no Programa de Pós-graduação em Ciência, Tecnologia e Educação

Centro Federal de Educação Tecnológica Celso Suckow da Fonseca

José Claudio Reis ${ }^{1}$

Universidade do Estado do Rio de Janeiro

Rio de Janeiro - RJ

\section{Resumo}

As pesquisas da educação científica indicam a necessidade de um ensino sobre as ciências que possa discutir os processos da mesma a fim de se distanciar de visões ingênuas e deturpadas. Dentro desta perspectiva, defendemos o diálogo entre ciência e arte como forma de entender o conhecimento científico como cultura de determinado local e época. Seguindo essa abordagem, faremos uma leitura, a partir de fontes primárias e secundárias, de alguns quadros da obra da artista surrealista espanhola Remedios Varo que ajudam a refletir sobre questões que permeiam a ciência. Para a leitura, traremos o contexto da artista junto a temas que a ciência esteve envolvida no século XX. Por fim, suscitaremos algumas questões combinadas a sugestões dessa leitura para o ensino, com o intuito de promover discussões que possam problematizar a ciência a fim de nos afastarmos de discursos cientificistas e autoritários.

Palavras-Chaves: Ciência e Arte; Ensino de Ciências; Remedios Varo.

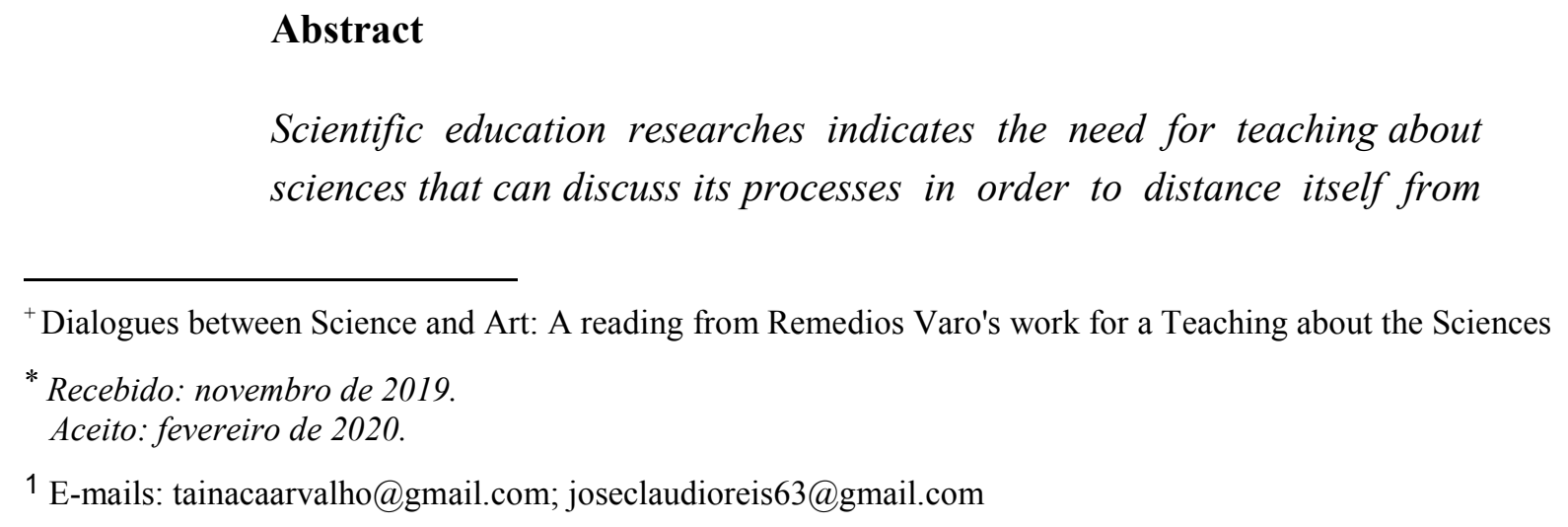

Scientific education researches indicates the need for teaching about sciences that can discuss its processes in order to distance itself from

\footnotetext{
${ }^{+}$Dialogues between Science and Art: A reading from Remedios Varo's work for a Teaching about the Sciences

* Recebido: novembro de 2019. Aceito: fevereiro de 2020.

${ }^{1}$ E-mails: tainacaarvalho@gmail.com; joseclaudioreis63@gmail.com
} 
naïve and misleading views. Within this perspective, we defend the dialogue between science and art as a way of understanding scientific knowledge as a culture of a given place and time. Following this approach, we will read, from primary and secondary sources, some pictures of the work of spanish surrealist artist Remedios Varo that help to reflect issues that permeate science. For reading, we will bring the context of the artist along with themes that science was involved in the twentieth century. Finally, we will raise some questions combined with suggestions from this reading for teaching, in order to promote discussions that can problematize science in order to move away from scientific and authoritarian discourses.

Keywords: Science and Art; Science Teaching; Remedios Varo.

\section{Introdução}

Não é novidade a frequência de pesquisas na área da educação científica que apontam a necessidade de um ensino que vá além dos conteúdos científicos, ressaltando, principalmente, os processos que a ciência propõe, comunica, avalia e legitima os seus produtos (IRZIK; NOLA, 2011; MARTINS, 2011; MOURA, 2014; OSBORNE et al., 2003; McCOMAS; ALMAZROA; CLOUGH, 1998; PRAIA; GIL PÉREZ; VILCHES, 2007).

A ampla discussão e defesa de um ensino sobre as ciências ${ }^{2}$ parte das dificuldades que encontramos na percepção que professores e estudantes têm sobre o conhecimento científico, algumas atreladas a imagens dogmáticas e deturpadas como a ideia de neutralidade e conhecimento absoluto (GIL-PÉREZ et al., 2001). Diante dessas discussões, compreendemos que há a necessidade de explicitar um ensino sobre as ciências, sobretudo problematizar suas escolhas e ações, pois ao evitar tais reflexões podemos estar nos aproximando de uma compreensão cientificista do conhecimento.

Defendendo um ensino sobre a ciência que a problematize, acreditamos que a arte se torna uma via possível para entendermos a ciência como um empreendimento cultural. Dentro da lógica da arte como cultura, compreendemos que os costumes, ideias, necessidades materiais e espirituais de uma cultura estão imersos na construção dos estilos artísticos, além da própria interação indivíduo-artista com essa cultura (OSTROWER, 1997 e 1998). É por meio dessa descrição da arte que nos aproximamos da ciência, pois ambas podem ser enxergadas como culturas, mesmo que sejam representadas com linguagens diferentes (REIS; GUERRA; BRAGA, 2006; ZANETIC, 2006). É importante ressaltar que ao mencionar o termo cultura

\footnotetext{
${ }^{2}$ Em alguns momentos usamos tal expressão a fim de reforçarmos o nosso posicionamento que compreende que a educação científica deve se direcionar para questões sobre a ciência.
} 
entendemos a compreensão de Geertz (1989) que a define com uma teia que homens estão entrelaçados e ao passo que essa teia determina suas ações, ela também é construída.

$\mathrm{O}$ diálogo entre arte e ciência no ensino não é recente. Há trabalhos em que obras artísticas e movimentos artísticos são utilizados para compreender fenômenos físicos ou auxiliar conteúdos científicos de determinados períodos (ANDRADE; NASCIMENTO; GERMANO, 2007; FERNANDES; PIRES; FORATO; SILVA, 2017; GALILI, 2013). Em nosso caso, propomos que a arte oriente discussões sobre a ciência e que os seus produtos possam ser discutidos à luz de determinado local e tempo.

Compreendendo que a arte não pode ser descontextualizada, assim como a ciência, acreditamos que os esforços de conduzir o ensino por meio da História e Filosofia da Ciência (FORATO; PIETROCOLA; MARTINS, 2011; GUERRA; BRAGA; REIS, 2010) são necessários à medida que por ela é possível aprofundar as relações entre ciência e arte. Por intermédio desta abordagem conseguimos entender a ciência como cultura, portanto um construto mutável e diversificado da natureza humana, além do fazer científico como um ato social, assim, imerso em relações de poder (MOURA; GUERRA, 2016). Acreditamos que ao compartilhar as representações artísticas articuladas aos processos históricos, explorando questões culturais que a ciência faz parte e a questiona, estamos contribuindo para um olhar mais humano sobre a construção dos conhecimentos científicos. Nesta perspectiva nos situamos dentro do campo da ciência e arte que se constrói atento para abordagens socioculturais focadas no ensino de ciências (ZANETIC, 1989; REIS; GUERRA; BRAGA, 2006).

Ao optarmos por um ensino de ciências em que a arte conduza discussões de determinado espaço e tempo, escolhemos a obra da surrealista espanhola Remedios Varo (19081963), uma artista do século XX que vivenciou acontecimentos importantes do período, como a Segunda Guerra Mundial e a Guerra Fria, e trabalhou como ilustradora científica. Em suas obras notamos discussões que envolvem as consequências dos atos de cientistas e instituições governamentais do período. Nesse cenário, Remedios retratou em alguns quadros ações da ciência que podem ser problematizados, principalmente, sobre uma visão de dominação sobre a natureza. Em contrapartida, a artista também ofereceu algumas telas que nos inspira a pensar sobre um entendimento mais real do conhecimento científico.

Assim, faremos uma leitura sobre algumas obras da artista que possam nos ajudar no ensino de ciências. Para tanto, nos orientaremos pela seguinte pergunta de pesquisa: "Que questões emergem de uma leitura da produção de uma artista plástica, também ilustradora científica temporária, do século XX que podem contribuir para um ensino sobre as ciências?".

Com a intenção de produzir a leitura, estruturamos o artigo da seguinte forma: inicialmente, apresentaremos a artista imersa nas culturas europeia e mexicana, escolhendo alguns momentos que são significativos para compor a rede cultural de Remedios a fim de compreendermos de onde a artista fala e o que ela representa. Em seguida, analisaremos alguns qua- 
$\operatorname{dros}^{3}$ em duas frentes: críticas sobre representações da ciência e um olhar mais plausível e humano para o conhecimento científico. Após isso, faremos a defesa de um ensino sobre as ciências em questões inspiradas nas propostas de Clough (2007) e Martins (2015).

\section{O que representa Remedios Varo: construindo o contexto do século XX}

Remedios Varo nasceu em 16 de dezembro de 1908 na cidade de Angles (Espanha) e é uma das filhas do casamento do engenheiro hidráulico Rodrigo Varo y Cejalvo com a dona de casa Ignacia Uranga Bergareche. É o seu pai que a incentiva no início de sua formação artística. Além das idas aos museus para conhecer a arte espanhola, ensinou-lhe desenho técnico ao pedir à jovem para realizar cópias dos seus próprios desenhos técnicos. $\mathrm{O}$ ensinamento de artes para mulheres fez parte da educação de outras artistas também, normalmente, as primeiras instruções artísticas eram ministradas pelos pais, irmãos ou tios, ou seja, alguma figura masculina (KAPLAN, 1988).

Em 1924 entra na Academia São Fernando de Madri, uma escola tradicional de artes da cidade espanhola, a fim de formar-se na área. Além dos cursos tradicionais, Varo realizou o curso de desenho científico que é significativo, pois é uma das amostras do seu interesse pela ciência. Durante os anos na academia conheceu o surrealismo e nele encontrou a possibilidade de experimentar novos estilos, diferentes da arte tradicional. A Arte Moderna abrange diferentes movimentos como cubismo, o expressionismo, futurismo, dadaísmo e o surrealismo, e estruturava as vanguardas do século XX. Os movimentos possuíam características diferentes, mas convergiam no ideal de contrariar uma descrição fiel do mundo (CRUZ, 2011). O surrealismo emerge na França e é identificado pela publicação do Manifesto Surrealista, em 1924, por meio do poeta André Breton (1896-1966). No manifesto foram exaltados os fundamentos do movimento, entre eles, o automatismo psíquico que consistia em expor o real funcionamento do pensamento (BRETON, 1924). Em Madri, o surrealismo se desenvolvia na Residência dos Estudantes que era o primeiro centro cultural e intercâmbio entre cientistas e intelectuais do período entre guerras com a intenção de estabelecer trocas culturais entre a Espanha e o restante da Europa (CALVO, 2009).

Durante a formação, Remedios conhece e casa com o artista Gerardo Lizarraga (1905-1983), um anarquista e posteriormente voluntário na defesa da República no decorrer da Guerra Civil Espanhola (CARREÑO, 2007). Após a formação e um ano em Paris, a jovem retorna para a Espanha em 1932 e escolhe Barcelona para residir, pois, naquele contexto, era a capital vanguardista do país e nela participou ativamente de círculos artísticos (CALVO, 2009; KAPLAN, 1988). É fundamental lembrar que em 1931 nascia a Segunda República, propiciando ao país passar por inúmeras reformas que tornaram o Estado mais democrático. A

\footnotetext{
${ }^{3}$ Como os quadros estão protegidos pelos direitos autorais não iremos representá-los neste artigo. Sendo assim, para acompanhar a leitura de análise aconselhemos o site Remedios Varo (disponível em: $<$ https://remedios-varo.com/>) que contém todas as obras mencionadas, além de outros quadros, e detém os direitos reservados. Todos os links aqui fornecidos foram acessados em fevereiro de 2020.
} 
Espanha sofreu algumas mudanças, como: reforma agrária, suspensão da censura para obras liberais de artistas, além de discussões sobre os direitos das mulheres (ALVES, 2015; KAPLAN, 1988). No entanto, em julho de 1936 iniciou-se a Guerra Civil Espanhola e durante os anos de guerra, a Espanha recebeu artistas e intelectuais que lutaram contra o totalitarismo e defendiam a Segunda República (SOUSA, 2016). Um dos exemplos é o poeta surrealista, participante do manifesto surrealista e amigo íntimo de André Breton, Benjamin Péret (18991959).

Péret e Varo se conheceram em 1936 e no ano seguinte, com o agravamento da guerra e caça aos defensores da República, Remedios decide residir em Paris com o poeta. A cidade reconhecida pelo número de intelectuais e a presença forte de Péret no movimento possibilitaram Remedios ingressar no grupo surrealista, porém ela resume sua atuação junto ao grupo como uma tímida ouvinte em meio a tantos nomes importantes da arte (KAPLAN, 1988). Os anos calmos em Paris terminaram com a chegada da Segunda Guerra Mundial em 1939 e a invasão alemã em Paris, além da prisão de Péret por causa do seu envolvimento político. Nesse contexto, Remedios foge com outros intelectuais e como uma refugiada, a primeira ocupação foi em Canet-Plage, localizado na costa do mediterrâneo e posteriormente, Marselha em que encontrou artistas que também estavam procurando abrigo durante o período. Foi em Marselha que encontrou Péret que havia conseguido sair da cadeia após subornar alemães.

Vale lembrar que no período da Segunda Guerra Mundial houve uma sensação por parte da sociedade de que a ciência tem um grande poder, e que pode ser utilizada para fins escusos e maléficos. O Projeto Manhattan e a ciência nazista são alguns exemplos dessa manifestação, mostrando ao mundo que a suposta neutralidade das instituições científicas era falsa e havia necessidade de olhar para as escolhas deste conhecimento e dos seus provedores. Adiantamos essa parte, pois é um fator importante para nossa leitura.

Somente em 1941 Remedios e Benjamin conseguem exílio no México, mas os primeiros anos no país foram difíceis. Os dois faziam parte de um grande grupo de imigrantes da cidade mexicana e Varo teve alguns trabalhos, por exemplo, pintora de móveis e ilustradora de campanhas publicitárias de uma empresa farmacêutica. O governo mexicano de Lázaro Cárdenas (1895-1970) possuía simpatia com os ideais da Segunda República e os ajudou com o envio de armamento durante a guerra (CRIPA, 2006; SOUSA, 2006), o que significou uma imigração em massa para o país ao longo dos anos. Muitos dos amigos de Varo foram para a Cidade do México e montaram um grupo que se afastava das comunidades nacionais artísticas ao tentarem recriar os estilos de vida europeia no país. Do outro lado, os artistas nacionais estavam preocupados com a invasão europeia, como o grupo do muralista Diego Rivera (1886-1957) que defendia uma arte com temática social, valorização da cultura indígena, representação de camponeses em cenas do cotidiano e via no surrealismo europeu uma arte intelectual e elitista. (CALVO, 2009; VASCONCELLOS, 2005).

Em 1947, Péret retorna à Paris, pois sentia saudade da vida parisiense, mas Varo prefere continuar na cidade mexicana. $\mathrm{O}$ interesse tanto pelo país como a cultura mexicana, com 
os trabalhos dos pré-colombianos, fazia parte da vida de Varo e era encontrada nas cartas que trocou durante os anos que esteve no país (RIES, 2010). No final de 1947, Varo viaja para Venezuela a fim de reencontra sua família. O irmão mais velho, Rodrigo Varo, se mudou para o país após se tornar chefe de epidemiologia do Ministério da Saúde Pública para dirigir uma campanha de controle de peste bubônica Com a influência de Rodrigo, Remedios consegue trabalho para realizar desenhos técnicos para um estudo epidemiológico do Ministério. Ela trabalhou no departamento de controle de paludismo que estudava os insetos parasitas, os portadores das doenças, e realizava desenhos para os estudantes (KAPLAN, 1988). É interessante dizer que Remedios faz parte de um grupo pequeno de mulheres que chegaram a ocupar a área de ilustração científica. São poucos os casos, durante os séculos, de mulheres nesta profissão, e quando atuavam, muitas das vezes, as participantes estavam ligadas a familiares, como esposas e filhas, de cientistas (CHANSIGAUD, 2016).

Neste período, vivia-se a Guerra Fria em que o mundo se dividia entre duas grandes potências: os Estados Unidos representando o sucesso do capitalismo e a União Soviética, o socialismo. Mesmo com as catástrofes das armas nucleares da Segunda Guerra Mundial e a sensação de medo pelas sociedades, a economia crescia nesse período com a preparação de guerras futuras e era incentivada pelos governos (HOBSBAWN, 1994). Nesse cenário de incentivo à indústria armamentista, os desenvolvimentos científicos e tecnológicos eram imprescindíveis. A Guerra Fria favorecia a Big Science, termo atrelado à ciência de grande escala, devido à necessidade de pesquisas que pudessem igualar as potências, estimulando as instituições científicas e universidades à criação de projetos que pudessem atender as demandas de agricultura e inovação industrial, por exemplos (JOSEPHSON, 2018).

Na volta para o México, em 1949, Remedios inicia, após alguns anos ainda de trabalhos publicitários, um rico período de criação artística. Nesse momento, estava casada com o refugiado austríaco e empresário Walter Gruen e pôde se dedicar às atividades artísticas. Com exposições coletivas e individuais, Varo ganhou prestígio na comunidade mexicana. As críticas positivas e um público crescente fizeram a artista participar regularmente de exposições no país (KAPLAN, 1988). No entanto, quase um ano após a segunda exposição individual da artista, em 1963, Remedios Varo morre aos cinquenta e cinco anos ao sofrer um ataque do coração. Após a morte da artista houve ascensão do público devido às exposições nos anos de 1964, 1971 e 1983 que promoveram sua arte. Além das exposições no México, as referências científicas em sua obra chamaram tanta atenção que exposições aconteceram em 1986 na Academy of Sciences de Nova York e na National Academy of Sciences de Washington.

Por fim, através do período relatado conseguimos apresentar a artista imersa no contexto do século XX e oferecer ao leitor subsídios que possam facilitar a compreensão dos caminhos temáticos que a artista adota em sua obra. Entendê-la como uma mulher exilada após a Segunda Guerra Mundial e em meio à Guerra Fria, sua criação e trabalhos nos ajudam a construir um panorama a fim de percebermos quais imagens de ciência a artista critica. Acreditamos que a leitura desta seção é essencial para trabalhos que utilizem a obra de Remedios, 
pois defendemos que toda arte precisa ser entendida a partir de quem a faz e em quais culturas o artista está inserido.

\section{Construindo uma metodologia para a leitura}

Pela seção anterior conseguimos compreender o que representa a imagem de Remedios Varo dentro de algumas culturas durante as primeiras décadas do século XX. A contextualização da trajetória da artista através da narração de alguns momentos de sua vida nos ajuda a localizá-la temporalmente diante de eventos que nos interessam, como os desdobramentos da Segunda Guerra Mundial, sobretudo o status que a ciência ocupa após esse momento. Desta forma, explicitamos discussões que permeiam a História da Ciência que serão úteis nesta leitura.

A intenção neste momento é buscar em seus quadros obras que nos remetem às problemáticas e representações sobre a ciência que ecoam da voz da artista, mas que estão presentes nas culturas que Remedios esteve presente. Em vez de buscar relações de causa e efeito entre sua obra e os conteúdos científicos, estamos construindo as análises dos quadros a partir de pontos significativos do período. Por outro lado, ao traçar tais questões das pinturas traremos algumas discussões que possam problematizar e repensar alguns discursos reducionistas sobre a ciência.

Para estruturar a leitura sobre a produção de Remedios construímos três pontos que compõem a análise de cada obra. No primeiro ponto, buscaremos situar a tela em seu contexto ressaltando o local em que foi feita e a atmosfera do período junto a uma descrição. Posteriormente, no segundo ponto, tratamos de algumas discussões já realizadas por alguns autores que contribuem nos estudos da obra da artista, além de comentários, quando for necessário, que a própria Remedios fez no verso de fotos das obras (VARO, 2018). Para esse ponto, chamamos atenção da autora Janet Kaplan que possui um rico trabalho biográfico e de análise dos quadros de Remedios Varo. Finalmente, no terceiro momento, além da visão desses autores e da artista, buscaremos reflexões, mediante as interpretações desse artigo, com o intuito de enxergar a potencialidade das imagens para um ensino sobre a ciência que a complexifique e questione o seu papel.

\section{A obra de Remedios Varo e as representações sobre as ciências: das críticas à pro- posta de reconciliação}

Nessa seção trataremos da produção artística de Remedios Varo nos anos que residiu no México entre as décadas de cinquenta e sessenta do século XX. A escolha desse período é justificável, pois nele é crescente o número de obras e é quando ela pode se dedicar integralmente às artes. Somado a isto, é antes desta fase que Remedios trabalhou como ilustradora de insetos e pode ter contato direto com uma comunidade científica. Além disso, ressaltamos que a artista recebeu de seu pai, um engenheiro hidráulico, uma educação em que a ciência era 
presente tanto pelas leituras de obras de ficção como dos desenhos técnicos que reproduzia. Nessas duas frentes, mesmo Remedios estando à margem das produções da ciência, não sendo considerada uma profissional da área, teve a possibilidade de enxergar de perto a atuação de cientistas.

Kaplan (1988) menciona que os estudos em áreas científicas, como biologia, química, física, astronomia e botânica faziam parte do cotidiano da artista no México. Além do interesse sobre novos conhecimentos, na obra de Varo podemos analisar críticas sobre os abusos, manipulações dos especialistas e os interesses, representados como inconsequentes, em controlar a natureza. Segundo a autora, a partir da obra dela enxergamos que a ciência precisaria adotar um papel não de domínio sobre a natureza, mas de harmonia e respeito.

Na primeira exposição coletiva no México, em 1955, Remedios apresentou quatro telas ao público, em que pode mostrar o seu amadurecimento artístico por meio de pinturas que abordavam temas de interesse da artista e mostravam o desenvolvimento de um estilo próprio. Um desses quadros é "Ciencia Inútil O El Aqluimista" (disponível em: <https://remediosvaro.com/la-ciencia-inutil/>) que além de mostrar o seu gosto pelos inventos, chama atenção para a alquimia.

Ao olhar para a pintura, vemos uma mulher sentada e tem o seu corpo encoberto por um véu que se torna o próprio piso do chão. Essa mulher gira a polia que integra o experimento e observamos tubos nas torres interligados às outras roldanas. Os conjuntos dessas roldanas fazem os sinos baterem e as rodas rotacionam, ventilando o ambiente como observamos através das bandeiras que balançam no ar. Além disso, o aparato complexo de máquinas recolhe do ambiente líquido que é transformada em um líquido verde que enche alguns frascos que estão em uma pequena mesa à esquerda no quadro.

Sobre essa tela de 1955, Calvo (2009) chama atenção que Remedios nos atenta para a mulher que mesmo estando em seu laboratório e guiando as transformações, ela pertence aquele experimento, como indica o chão do local que se integra à alquimista. Dentro dessa perspectiva, a representação de um sujeito que se distancia do seu objeto de estudo e somente faz interferências sobre ele perde o sentido ao olharmos para essa obra, em que a alquimista faz parte da ação e não há como retirar sua presença.

Ressaltamos que mais do que apresentar um ambiente para a alquimia, essa obra é significativa por causa do seu título. Remedios ao intitular de: "Ciência inútil ou o alquimista" (em tradução livre) nos provoca ao mencionar que os estudos sobre a alquimia fariam parte de uma ciência inútil. Podemos nos perguntar: inútil para quem ou que? Dentro dessa análise, não podemos esquecer que esse quadro é feito após a primeira metade do século XX, em que a alquimia é vista como uma pseudociência, pois é desde o século XVIII que a química se instala como um conhecimento científico e se distância das atividades da alquimia (NUMMEDAL, 2016). Entendemos que, por meio desse título, Remedios pode nos sugerir um julgamento de valor de um conhecimento superior, a ciência, sobre o outro, a alquimia, que a reconhece como um conhecimento inútil, não pertencente ao seu domínio. No entanto, essa 
visão é simplória, pois não reconhece as contribuições da alquimia para a construção do conhecimento científico.

A recente historiografia da alquimia, apontada por Nummendal (2016), vem investigando que a combinação entre teoria e prática, características da ciência moderna, é uma herança dos alquimistas, pois eles têm como processo de investigação a manipulação da matéria junto às especulações teóricas. Somado a isto, a tradição textual associada à escrita e manutenção dos textos a fim de estudá-los, além da busca de conhecimentos de outros autores, aparecem como práticas dos alquimistas dos primeiros séculos e constituem práticas científicas fundamentais da ciência até hoje (NUMMEDAL, 2016).

Somado a essa ideia, a própria concepção de uma Revolução Científica para o nascimento da ciência moderna tem sido contestada. O pensamento de um movimento abrupto, como sugere o conceito de revolução, tem sido revisto e mostrado que o novo mundo, inaugurado com essa caracterização, está imerso em conhecimentos que dialogam e resgatam o velho mundo. Exemplos que justificam esse olhar são os estudos que mostram a medicina moderna europeia bebendo nos trabalhos da alquimia chinesa (LIVINGSTONE, 2003). Ao invés do conceito que surge ao pensarmos em uma Revolução Científica, esse novo olhar enxerga tal período como um processo gradual de desenvolvimento e expansão em que o contato com novas culturas, como a chinesa citada, possibilitou a ampliação de horizontes da ciência europeia (PIMENTEL, 2007).

Remedios Varo ao trazer esse título nos oferece uma reflexão que vai além de pensar somente na alquimia, mas mostra uma visão de ciência em que o conhecimento científico, através de conjunturas culturais e sociais, realiza apagamentos nas contribuições de outras formas de conhecer a fim de se estabelecer como superior e único. Além do mais, essa obra é importante, pois está imersa em um discurso da metade do século XX que expõe a ciência como sinônimo de progresso socioeconômico, e contribui para repensar como esta representação exclui a possibilidade de conceber e produzir conhecimentos que não façam parte da ciência (SANTOS, 2008). Nesse movimento de demarcar o que é ou não ciência, há também a possibilidade de desqualificar o que é divergente e não acompanha os seus métodos.

Com o sucesso da exposição coletiva em 1955 e a exposição particular no ano posterior, Remedios foi reconhecida entre os intelectuais e a sociedade abastada mexicana. As artes eram cada vez mais mercantilizadas nas galerias e exposições, o que era perfeito para a obra de Remedios (VASCONCELLOS, 2005). Naquele contexto ter um retrato pintado por um artista era sinônimo de luxo, ainda mais na cultura mexicana da época que os artistas mexicanos eram reconhecidos pela obra monumental feita em grandes muros e com temas sociopolíticos, desvirtuando da ideia de um retrato. Durante o período de reconhecimento e valorização da sua arte, Varo recebeu algumas encomendas no ano de 1957 e realizou retratos de pessoas que formavam a elite mexicana (KAPLAN, 1988). Um desses exemplos é o retrato do famoso e prestigiado cardiologista mexicano Ignacio Chávez (1897-1979) que recebeu o nome de 
“Retrato Del Dr. Ignacio Chávez" de 1957 (disponível em: <https://remediosvaro.com/retrato-del-doctor-ignacio-chavez-1957/>).

Diferente de um retrato convencional do médico que ele pudesse ser representado como uma figura imponente, Remedios retrata-o de forma tímida, observamos pouco do seu corpo e sua prática médica fica mais evidente. Nesta obra é apresentado Ignacio dentro de um ambiente com escadas ao fundo, podendo ser o seu consultório, e ele faz o atendimento dos seus pacientes que formam uma fila. $\mathrm{O}$ cardiologista está com uma vestimenta diferente de um jaleco tradicional médico, sua roupa se aproxima de um manto como se fosse um sacerdote da sua profissão (VARO, 2018). Enxergamos as pessoas que formam a fila apresentam no lado esquerdo do peito, "o local do coração", uma porta que apresenta uma fechadura. Nas figuras que esperam o atendimento, a porta está aberta, mas Doutor Ignacio detém a chave que consegue fechar a porta, como observamos no paciente que está sendo atendido.

Em uma primeira análise podemos encarar que a medicina, encarnada na figura de Chávez, possui a cura, a chave, sobre as enfermidades do coração, a porta aberta, e o dever do médico o coloca em posição de sacerdote. Por outro lado, a obra de Varo nos oferece representações complexas sobre o papel desse médico e sua área científica. Kaplan (1988) menciona que no retrato de Ignacio, Remedios faz uma crítica sobre o controle que os médicos possuem sobre as pessoas que se comportam como fossem marionetes dos seus estudos, uma espécie de ridicularização da profissão médica através da ideia de manipulação da vida. A figura da marionete faz sentido ao olharmos as articulações dos pacientes que estão interligadas ao céu por meio de cordas. Somado ao que Kaplan (1988) diz, o corpo é posto como uma estrutura de máquina em que o seu defeito é resolvido através dos conhecimentos científicos. Essa visão de mundo como máquina em que a ciência possui o controle transparece a noção mecanicista que pode ser encarada como uma das bases da ciência moderna (SANTOS, 2008).

Santos (2008) menciona que na lógica mecanicista, a natureza é passiva, eterna e vista como uma máquina em que o homem tem poder de dominar e controlá-la. Esse poder é oriundo do saber científico que produz um conhecimento útil e funcional, um dos resultados dessa visão é a desqualificação de qualquer outra forma de conhecimento em nome de combater os discursos dogmáticos e de autoridade. No entanto, esse próprio movimento produz uma espécie de dogmatismo, o cientificismo, na sociedade. A perspectiva de um conhecimento capaz de resolver qualquer problema, transmitida pela tela, faz parte de uma cultura cientificista presente no século XX, em que as escolhas da ciência estariam voltadas para o bem-estar social. É importante destacar que ao trazer essa obra e realizar essa discussão não estamos dizendo que a medicina, ou em nível mais geral: a ciência, deve ser esquecida ou substituída por outro conhecimento. No entanto, é fundamental que tenhamos a noção de até onde a ciência pode responder ou não os problemas a fim de não ficarmos reféns de discursos que a use para legitimar suas práticas. O quadro de Doutor Ignacio nos ajuda a repensar sobre qual olhar os leigos podem assumir a respeito das atuações científicas, não incorporando a passividade, 
como as marionetes, mas questione ações científicas e crie um diálogo constante com aquele que detém a autoridade científica. Acreditamos que ao problematizar esse conhecimento, desvelamos os interesses envolvidos e atentamos para os riscos que tais práticas podem produzir para a sociedade.

Ainda nessa obra, chamamos atenção na forma que o médico é apresentado. Sua vestimenta o difere dos personagens que compõem a obra, a túnica vestida confere a ele a imagem do sacerdócio. Ele não é qualquer pessoa, é um profissional que recebe a vocação para ser um homem da ciência. A representação do cientista de intelecto acima da média e recluso da sociedade se assemelha à figura de Doutor Ignacio. O médico representa a figura do gênio isolado que detém o conhecimento científico e sai do seu local para salvar vidas de quem necessita.

Esta tela nos estimula em pensar em algumas questões, como: quem é esse cientista? O que ele representa em determinada cultura? Qual o poder das ações deles nas vidas das pessoas que constituem determinada sociedade? Os cientistas, assim como qualquer outra profissão, estão imersos em relações sociais de poder. Eles disputam projetos de financiamento para suas pesquisas e nessas defesas precisam se comunicar com diferentes setores das sociedades, como instituições governamentais e empresas privadas, a fim de mostrar o potencial de suas pesquisas, assim imersos em relações de poder (VIDEIRA, 2007; MOURA; GUERRA, 2016; RUDOLPHE; HORIBE, 2016). Olhando para a construção das bombas atômicas durante a Segunda Guerra Mundial e a corrida armamentista durante a Guerra Fria, os cientistas não estão somente envolvidos nas produções, mas no convencimento dos órgãos governamentais da necessidade de investimento nesse tipo de armamento. Junto à imagem e as reflexões aqui descritas, percebemos a potencialidade desta pintura para questionar a figura do gênio isolado.

Não é somente em "Retrato del Dr Ignacio Chávez" que Remedios expõe algumas imagens sobre o cientista. Outro exemplo é "Planta Insumisa" (disponível em: $<$ https://remedios-varo.com/planta-insumisa-1961/>) de 1961. É interessante lembrar que neste ano, Remedios já havia trabalhado no laboratório na Venezuela, onde teve contato com pesquisadores que estudavam insetos a fim de combater doenças que esses animais são os transmissores.

No quadro, não vemos apenas os estereótipos do cientista, através do cabelo bagunçado e jaleco, mas representações do olhar da ciência sobre a natureza e o seu processo de sistematização por meio da matemática. Remedios retrata um cientista, mais especificamente um botânico, que estuda a vida vegetal. Ele está com sua bancada de trabalho em um ambiente aberto, diferente do laboratório, como podemos verificar através dos arbustos que aparecem no solo e as árvores ao fundo do cenário. Na bancada há algumas plantas que crescem aos cuidados do homem como podemos ver pelos regadores que estão em cima da mesa também. Através dos olhos do cientista, as plantas possuem números em suas ramificações e as folhas são formadas por fórmulas químicas, as garrafas de água apresentam números e o próprio botânico tem fórmulas matemáticas que compõem o seu cabelo. 
No entanto, uma planta chama atenção do botânico que a observa com cuidado. Esta planta, chamada de insubordinada como sugere o título da obra, não segue as fórmulas. Kaplan (1988) diz que a planta em tom de rebeldia, contra a visão do cientista que a domestica, não segue as formulações, mas a natureza ao seu redor que não acompanha a sistematização matemática. A própria Remedios comenta mais sobre essa planta, segundo ela:

O cientista está experimentando várias plantas e vegetais. Ele está confuso porque tem uma planta rebelde. Todas já estão lançando seus galhos na forma de figuras e fórmulas, exceto uma que insiste em produzir uma flor, e o único galho matemático que foi enviado no começo e que cai sobre a mesa era muito fraco e definhado e, além disso, errado, já que diz: "Dois e dois são quase quatro". Todo cabelo do cientista é uma fórmula matemática (VARO, 2018, p.110-111, tradução nossa).

"Planta Insumisa" pode assumir mais uma crítica sobre os modos operantes da ciência e o olhar de posse sobre o seu objeto de pesquisa. A obra simboliza a imagem do conhecimento científico, através do botânico e sua lógica de trabalho, e retrata a forma que ele age sobre a natureza. Nesta representação, a ciência trata de entender a natureza por meio da abstração matemática, em um processo de ambição e buscando controlá-la. No entanto, é durante o procedimento que a ciência acaba se alienando da própria natureza, seu ponto de partida (KAPLAN, 1980 e 1988).

Dentro dessa lógica de uniformização por meio das descrições matemáticas, o botânico esquece que o seu objeto é um organismo vivo que faz parte de um ecossistema com uma diversidade. Calvo (2009) ao analisar essa obra menciona que se um conhecimento é apresentado como meio de controle do espaço, pois representaria a essência da realidade, tudo aquilo que está fora dele é irrelevante. É através desta ideia que nos aproximamos do totalitarismo de um conhecimento sobre outro. A preocupação não está na opção de escolher os modelos científicos a fim compreender o funcionamento da natureza, mas o medo de esquecer que estamos tratando e fazemos parte dela. Nesse quesito, o quadro se justifica ao pensarmos que ele está imerso nos acontecimentos do século XX, como o desenrolo da Segunda Guerra Mundial e a Guerra Fria, em que a ciência teve um papel importantíssimo e desastres ambientais e humanitários ocorreram (HOBSBAWN, 1994). Ortiz (2011) chama atenção para a desnaturalização que o botânico faz sobre aquelas plantas, ao realizar os procedimentos de generalizações e formulações de leis, essa planta perde a localidade daquele ambiente e entra em um processo de universalização. Nessa lógica, o trabalho de Livingstone (2003) se esforça ao manifestar a ciência como local através da noção de uma geografia da ciência que explora a localidade do conhecimento científico em contraste com a ideia de universalidade.

Remedios Varo, em outro exemplo de 1961, nos apresenta as consequências extremas e últimas da perda de sensibilidade do pesquisador sobre o seu objeto, em que o produto dessa abstração científica é a destruição da própria natureza. Em "Descubrimiento de um Geólogo mutante” (disponível em: <https://remedios-varo.com/descubrimiento-de-ungeologo-mutante-1961/>) observamos um cientista, mas especificamente um geólogo, que 
possui uma cauda de guaxinim e asas, caracterizado como um mutante conforme sugere título. Ele está em um espaço devastado e de clima desértico, como vemos através das muitas ruínas que ocupam o local e a areia que preenche o solo. Não vemos uma vegetação consistente no espaço que o geólogo estuda, há somente uma única flor que cresce de forma exuberante nesse ambiente e é ela que chama total atenção do cientista. Varo (2018) resume o quadro em "uma paisagem devastada pela bomba atômica, um geólogo, mutante por causa da radiação, examina uma flor gigantesca. O geólogo é carregado com um laboratório de instrumentos muito interessante" ${ }^{\prime 4}$ (p. 110, tradução nossa).

O geólogo analisa a planta através da sua lupa que está associada à sua bancada experimental. A bancada é móvel, como observamos através das rodas que estão na base, sugerindo que esse cientista está à procura de alguma vida nesse lugar inóspito e parou quando encontrou esse sinal de vida. Além de ser móvel, a bancada possui seus aparatos experimentais e algumas mudas de plantas que ele cuida com muito cuidado como observamos por meio das gotículas de água que as regam.

Kaplan (1988) diz que Remedios ao pintar esse cenário faz alusão aos locais mais próximos das zonas afetadas pelas bombas atômicas em Hiroshima e Nagasaki no ano de 1945. Podemos recordar que o Projeto Manhattan, liderado pelos Estados Unidos, foi o responsável pela construção das bombas e teve como protagonistas cientistas e o governo norteamericano, resultando no lançamento das bombas em território japonês. Nesse cenário de pósguerra, há a compressão de que o homem através da ciência poderia controlar a natureza, tornando-se refém das ações dele, resultando em medo e desconfiança pelas sociedades (HOBSBAWN, 1994).

Mesmo com os ataques e o fim da Segunda Guerra, o medo sobre novas catástrofes pairava o ar do século XX através da Guerra Fria. A disputa ideológica entre as duas superpotências, EUA e URSS, enxergava na corrida armamentista o potencial de se rivalizarem e mostrarem o poder que cada país detinha. A sensação que ataques nucleares pelo globo poderiam acontecer em qualquer situação era uma realidade, mesmo que as duas nações entendessem que as armas poderiam resultar em um pacto suicida. A economia referente ao comércio de armas em conjunto ao ideal da Big Science crescia nesse ambiente, homens e instituições aumentavam seus lucros na preparação de futuras guerras. Nesse período de incentivo à indústria armamentista, os desenvolvimentos científicos e tecnológicos eram fundamentais (HOBSBAWN, 1994).

O quadro de 1961 é pintado dentro desse contexto da Guerra Fria e ameaça nuclear em que a ciência tem um papel fundamental. Pensar em uma ciência neutra que serve ao bem ou ao mal não atende a complexidade que esse quadro nos transmite. A ciência é construída em nome de interesses individuais e coletivos, assim não há como distanciar os seus produtos

\footnotetext{
${ }^{4}$ Tradução livre dos autores do trecho: In a landscape devastated by the atomic bomb, a geologist, mutant because of the radiation, examines a gigantic flower. The geologist is loaded down with a very interesting instrument-laboratory (VARO, 2018, p.110).
} 
de quem os produz ou financia, ou assumir a postura em que a ciência está restrita a conhecer a natureza e estabelecer o bem-estar social (VIDEIRA, 2007). Em vez dessa concepção, a ciência é feita por cientistas que possuem crenças e ideologias variadas, assim não há como separar os trabalhos de quem eles representam e defendem. É compreender a ciência com seus limites e perigos intrínsecos em suas atividades, pois ela envolve um número grande de variáveis, como financiadores, crenças, questões morais, ideológicas e espaciais, logo não há como adotar uma postura ingênua de ciência neutra (LIVINGSTONE, 2003; VIDEIRA, 2007). Por isso, existe a necessidade de uma formação que forneça a população leiga mecanismos para identificar os riscos que qualquer discurso científico pode oferecer a natureza (HODSON, 2010; BAKER; ORESKES, 2017).

Continuando na representação de uma ciência que quer o controle e domínio sobre o mundo natural, a autodestruição é um dos efeitos possíveis que vemos nesta obra. Falamos em autodestruição, pois o próprio cientista imerso no espaço também está sofrendo transformações por causa da explosão da bomba. Mesmo mergulhado na sua investigação, ele está sofrendo uma mutação, vistos através da cauda do guaxinim e as asas de insetos que formam o seu corpo. $\mathrm{O}$ exagero da mutação reforça a ideia que ao destruir em nome do progresso também permitimos a destruição de nós mesmos, pois dependemos dos recursos que o ecossistema nos oferece, além de sermos parte dele.

Até agora passamos por produções da Remedios Varo em que construímos uma leitura sobre as representações da ciência em torno das ideias de dominação acerca da natureza e as consequências dessa visão para a humanidade. Em paralelo a elas há também a exposição da figura do gênio isolado como vimos anteriormente. Em contrapartida a essas visões, a artista manifesta outra representação que exemplificaria o fazer científico. Segundo Kaplan (1988), Varo entende que a ciência deve ser aberta ao novo e sendo assim, pode encarar as múltiplas possibilidades e ver, com humildade, o potencial do desconhecido.

Dentro dessa perspectiva, podemos analisar com atenção o quadro "Revelación o el Relojero" (disponível em: <https://remedios-varo.com/revelacion-o-el-relojero-1955/>) de 1955. Nele vemos um homem bem vestido que está sentado e aparenta estar assustado com o que vê, os objetos que estão na mesa caem com o susto do rapaz. Ele é o relojoeiro conforme identificamos através do título da pintura e o local em que se encontra. O espaço é fechado e o ambiente é de trabalho como enxergarmos por meio dos relógios que o compõe e sua mesa que possui engrenagens que fazem parte das montagens dos relógios, além da presença de instrumentos, como a lupa e ferramentas. A sala possui oito grandes relógios que o rodeiam, todos eles apontam a mesma hora, mas a base de cada relógio contém uma personagem com diferentes vestimentas que marcam diferentes períodos da história. Em um dos relógios avistamos um homem com trajes do Império Romano e outro com traje das dinastias egípcias.

Voltando para o relojoeiro, ele se encontra paralisado com a revelação que se aproxima dele (VARO, 2018). Essa revelação é retratada como um disco, envolto a uma névoa, que gira e entra através da janela da sala, interrompendo o homem que estava trabalhando em 
sua mesa. Kaplan (1988) menciona que os relógios da sala representam o sistema newtoniano para o tempo. Nesse sistema, o tempo é uma grandeza absoluta e imutável, sendo invariável para referenciais diferentes, como observamos nos relógios que marcam o mesmo horário, mas em momentos históricos diferentes como assistimos por intermédio das diferenças nas vestimentas dos personagens que compõem os relógios. Em alternativa, a figura misteriosa apresenta-se como a revelação dos estudos da relatividade restrita, a qual explicaria a dilatação temporal e a contração espacial. Através das pesquisas sobre o tempo e espaço desenvolvidas no final do século XIX e início do século XX, o tempo pode ser compreendido como um ente relativo, que passa de forma diferente para referenciais distintos.

Kaplan (1988) cita que em contrapartida do botânico que não admite a planta fora do seu controle como vemos através de "Planta Insumisa", o relojoeiro olha abertamente para o novo conhecimento, mesmo que ele tenha que rever o seu sistema e transformar o seu olhar sobre o seu objeto. Se "Planta Insumisa" pode existir a ridicularização da posição do cientista arrogante, na obra do relojoeiro temos o aspecto mais satisfatório da ciência que é estar aberta para novos conhecimentos, não aceitando a possibilidade de um conhecimento que seja atemporal e absoluto.

Após oito anos do "Revelación o el relojoeiro", Varo retrata no próximo quadro a versão completa da relatividade, ilustrando o espaço-tempo que é um dos conceitos fundamentais na Teoria da Relatividade Geral. Cabe dizer que em 1963, ano da criação do quadro, este tema é amplamente reconhecido no imaginário da cultura ocidental, muitas vezes ligado ao nome do cientista Albert Einstein que recebera um nobel em 1921 e era um nome de prestígio, mesmo já falecido desde 1955 (KAPLAN, 1988).

Em "Fenómeno de ingravedad" (disponível em: <https://remedios-varo.com/feno meno-de-ingravidez-1963/>) de 1963 vemos um cientista, uma figura híbrida que une características físicas e a curiosidade de Varo junto à masculinidade do pai conforme outras figuras da ciência representadas em seus quadros (KAPLAN, 2010), que se atenta para uma nova experiência. $\mathrm{O}$ astrônomo ocupa um espaço que possui algumas peculiaridades como a estante que dispõe alguns modelos do sistema solar que explicariam as posições dos astros. No entanto, o que chama atenção é o espaço deformado, como identificamos por intermédio das paredes, solo e janelas que parecem estar distorcidos. O cientista vê com atenção e assombro que Lua e Terra, retratados pelos dois globos, não estão mais associados à força gravitacional que compõe a explicação dos modelos que estão em sua estante, mas o tecido do espaço-tempo que descreve a interação entre os dois (KAPLAN, 1988). O tecido espaço-tempo representado pelo quadro é deformado pelos astros ao mesmo tempo em que explicaria também o movimento destes corpos celestes.

Esse quadro é tão significativo por causa da representação do espaço-tempo que em anos mais tarde foi utilizado para ilustrar a capa do livro "The Riddle of Gravitation" do cientista Peter Bergmann (FRIEDMAN, 1997). Nesse livro, há um texto científico que apresenta conceitos importantes das teorias cosmológicas para a gravidade tanto de Newton como de 
Einstein. A fusão dos conceitos de espaço e tempo através dos estudos da Teoria da Relatividade Geral que aconteceu nos primeiros anos do século XX mostrou o quanto a física não estava fechada, mas aberta para novos estudos e teorias (GUERRA; BRAGA; REIS, 2010; REIS, 2015). Kaplan (1988) identifica que o assombro do cientista é por perceber que as forças estão fora do seu controle, mas ele compreende a verdade científica como relativa e aberta para novas formulações. Segundo a autora, a artista tem o entendimento que o conhecimento científico é mutável, não sendo constituído por verdades absolutas e sua preocupação está em uma imagem de ciência fechada para novas questões.

Através de "Fenómeno de ingravedad" não só conseguimos entender o conhecimento científico como mutável por meio das novas concepções de espaço e tempo que a Teoria da Relatividade nos oferece, em contrapartida as noções absolutas da dinâmica newtoniana, mas podemos também compreender a temporalidade da ciência. Quando falamos em temporalidade não estamos só pensando que a ciência muda ao longo do tempo, mas também que o conhecimento científico é o produto de determinado espaço e tempo (LIVINGSTONE, 2003). Os trabalhos de Einstein que resultaram nas ideias de espaço e tempo relativos ou tecido espaço-tempo são resultantes de questionamentos que nos levam a outras vozes que compõem essa rede cultural desde a comunidade científica até o mundo das artes (JONES, 2008; HENDERSON, 2008). Refletir sobre esses conceitos e a ideia de uma quarta dimensão fazia parte da cultura europeia do final do século XIX e início do XX.

Nesse sentido de temporalidade e conhecimento construído por diversas mãos conseguimos ir além da figura do gênio. Einstein não é um gênio que se isola para desvendar o universo, ele é um homem do seu tempo que está imerso em uma cultura onde a quarta dimensão é uma questão (JONES, 2008; GALISON, 2005). Ele não está sozinho investigando esse tema, ele tem contato com uma comunidade científica que discute as fragilidades de teorias anteriores que não são capazes de responder certas questões (GUERRA; BRAGA; REIS, 2010; REIS, 2015). Ainda sobre a mutabilidade e temporalidade, é importante chamar atenção que a universalização, um dos sinônimos de sucesso para um estudo científico, tende a apagar essas características. E quando percebemos fragilidades, partes que a teoria "universal" não responde, podemos embarcar em uma descrença sobre a ciência que é infundada, pois ela atende a determinados problemas e são novos questionamentos que levam a outros conhecimentos. Por isso, não há como desassociar as particularidades, como as indagações e motivações, que determinado espaço e tempo expõe com os produtos da ciência, pois é através dessa associação que a percebemos como um empreendimento humano e cultural.

Enfim, percebemos que através desses quadros e a contextualização deles conseguimos levantar algumas questões que podem nos ajudar a pensar em um ensino sobre a ciência. Ao problematizarmos questões cientificistas, como um conhecimento que se enxerga superior a outros ou renega suas bases, ao falarmos sobre a mutabilidade e temporalidade da ciência, acreditamos que estamos nos distanciando de posturas totalitárias e nos aproximando de uma visão que entende a ciência como conhecimento construído por pessoas em um local e tempo. 
Nesse sentido, a arte, em específico os quadros da Remedios Varo, contribui nessa intenção ao trazer temas e questionamentos que são pertinentes ao tempo em que foram criados.

\section{Por um ensino de ciências em questões: algumas reflexões e implicações}

Em vez de propormos uma estruturação em que as obras possam ser exploradas sistematicamente, trazemos algumas reflexões que aliadas à leitura das telas possam ser importantes para provocar debates em sala para um ensino sobre a ciência e podem servir como ponto de partida para a construção de propostas específicas. Fazemos essa opção por entendermos que cada realidade escolar possui suas especificidades e compreendemos que o professor é a melhor pessoa para decidir o que pode ser feito ou não em seu ambiente de trabalho.

Diferente de termos um conteúdo em que as obras possam ajudar na motivação ou entendimento, acreditamos que a leitura feita pode oferecer momentos de reflexões sobre a produção do conhecimento. Desta forma, compreendemos que não há uma disciplina específica ou período correto para discutir as obras, mesmo que estejamos tratando de discussões de uma artista do século XX. Concebemos que à medida que o professor perceba que discursos cientificistas, dogmáticos ou visões deturpadas sobre os cientistas pairam na sala de aula, os quadros podem ser apresentados desde que haja a apresentação da obra de Remedios Varo e o contexto de sua produção, aliados a discussões que permeiam a História da Ciência como abordamos na leitura dos quadros.

Para compor esta seção, nos inspiramos, inicialmente, na proposta de questões e temas de Martins (2015). Neste trabalho, o autor defende o ensino em eixos temáticos e questões, em que estas possam conduzir os conteúdos científicos. No entanto, em vez de utilizarmos as questões propostas pelo autor, criaremos algumas a partir das obras. Assim, trataremos de um ensino sobre a ciência que foge da ideia de princípios, tão comum na Natureza da Ciência (NdC), como sugere o trabalho de Clough (2007) que propõe os questionamentos em vez de declarações. Acreditamos que a abordagem em questões empregadas nos estudos de Martins (2015) e Clough (2007) podem fomentar momentos de reflexão e debates para um ensino sobre a ciência. De outro modo, ao optar por questões conseguimos responder a pergunta inicial de pesquisa: "Que questões emergem de uma leitura da produção de uma artista plástica, também ilustradora científica temporária, do século XX que podem contribuir para um ensino sobre as ciências?”.

Em "Ciencia inútil o el alquimista" (1955) enxergamos que através da leitura da obra podemos formular questões sobre as formas de produção do conhecimento, como ele consegue ser o encontro de outros saberes ressignificados. Chamamos atenção para o fato da alquimia ser representada como uma ciência inútil, o que é um fator interessante de ser abordado também, pois expõe a imagem da ciência ser superior a qualquer outro saber. Apoiandonos em Martins (2015), conseguimos formular questões como: Há um conhecimento superior ao outro? O que faz um saber ser melhor que o outro? A ciência está a frente de qualquer outro conhecimento? Como dizer o que faz parte da ciência ou não? Tais questões são alguns 
exemplos que podem orientar as discussões em sala de aula. Nesse sentido, o professor pode ressaltar os aproveitamentos que a medicina tradicional utiliza da própria alquimia. É importante também ressaltar o contexto do quadro a fim de entender de onde essas ideias de superioridade científica e demarcação do que é útil ou não emergem. Para isso, o professor pode explicitar alguns equívocos apontados por Pimentel (2007) sobre a Revolução Científica, como a própria ideia de revolução abrupta do conhecimento e o resgate do antigo pelo novo conhecimento, e as semelhanças de práticas entre a alquimia e as ciências a fim de contrapor o ideal de superioridade da ciência moderna (NUMMEDAL, 2016).

Na tela "Retrato do Dr Ignacio Chávez" (1957) acreditamos em debates sobre a figura dos cientistas. Situar o quadro como uma encomenda para um prestigiado médico do México pode enriquecer a argumentação sobre a influência que a voz da ciência obteve naquela sociedade e podemos fazer também um paralelo com a realidade atual em que a opinião do cientista é presente nos meios de comunicação, como a validação dos acontecimentos. $\mathrm{O}$ professor pode ter em mente algumas questões, como: Podemos pensar em função social dos cientistas? Há possibilidade de um cientista fazer o que bem entende em suas pesquisas? Como ocorre o diálogo entre cientistas e leigos? O professor pode chamar atenção na forma que o cientista é representado e perguntar se eles são realmente assim. Por outro lado, o estado de como os pacientes são atendidos possibilitam outras discussões, como a forma que os alunos se atentam para a atuação da ciência sobre a vida deles, usando até mesmo o exemplo das consultas médicas, se há um diálogo ou somente imposições de um discurso. Como exemplo, podemos mencionar o incentivo para o uso de anticoncepcionais e a escassa comunicação dos efeitos colaterais que eles apresentam ${ }^{5}$.

Apelamos também para a visão mecanicista que o quadro evidencia e como tal visão retoma a ideia de controle. Sugerimos atenção para a explicação sobre o mecanicismo e o que ele tem de consequências para as sociedades do século XX. Para isso, a discussão de Santos (2008) sobre a construção da superioridade científica pode ser aproveitada em sala de aula, como a atuação dos cientistas durante a Segunda Guerra Mundial que demonstram a associação deles com as instituições (HOBSBAWN, 1994; JOSEPHSON, 2018).

Em "Planta Insumisa" (1961) as discussões podem seguir um caminho epistêmico, através de algumas questões: O que é um modelo científico? Como os modelos científicos atendem as demandas da ciência? Os modelos possuem limites? As questões associadas às características do quadro, como o caso da planta insubordinada que se difere das outras, são fecundas para debater as validades dos modelos e o que eles respondem nos estudos. Como a tela é construída em um cenário de pós-guerra, sugerimos debates que envolvem a atuação da ciência nazista nos campos de concentração durante a Segunda Guerra Mundial a fim de discutir os modelos científicos e os seus limites (HOBSBAWN, 1994). Além disso, há como pensar na ideia de controle da ciência sobre a natureza, em como o cientista alienado das suas

\footnotetext{
${ }^{5}$ Sobre esse assunto indicamos a matéria da BBC Brasil. Disponível em:

$<$ https://www.bbc.com/portuguese/geral-38607880>. Acesso em: fev. 2020.
} 
práticas acaba esquecendo que está tratando da vida natural. Nesse sentido, podem ser debatidas quais consequências emergem quando há essa apatia do homem sobre o seu objeto de estudo.

Se em "Planta Insumisa" há como fazer implicações sobre os mecanismos de controle, em "Descubrimiento de um geólogo mutante" (1961) há como trazer implicações sobre as consequências devastadoras de certas ações. A tela é produzida no contexto de pós Segunda Guerra Mundial e da Guerra Fria tem o potencial de levantar discussões sobre neutralidade da ciência, nesse sentido sugerimos algumas questões, como: Há ciência para o bem ou para o mal? É possível pensar em neutralidade da ciência? Toda pesquisa científica possui riscos? Os riscos são bem comunicados para a sociedade? Há como melhorar essa comunicação entre cientistas e sociedade? Nesse sentido, o professor pode propor debates em torno do Projeto Manhattan e os empreendimentos de crescimento econômico que envolvem a Big Science e a corrida armamentista durante a Guerra Fria (HOBSBAWN, 1994; JOSEPHSON, 2018).

O debate pode ser explicitado com a menção das instituições de pesquisas que disputam financiamentos para seus estudos através de editais que ditam o que deve ser pesquisado. Com essa situação surgem novas questões como: $\mathrm{O}$ cientista pode pesquisar o que quiser? $\mathrm{O}$ que ou quem determina o que será pesquisado? Nessa lógica, os debates que envolvem o Projeto Manhattan, a Big Science e a corrida armamentista podem ser resgatados aqui também. Chamamos atenção para a figura do geólogo de "Descubrimiento de um geólogo mutante", pois ela é impar e pode potencializar a aula, pois a própria mutação dele reflete que a humanidade também é afetada pelos seus atos.

Nos quadros "Revelación o el relojoeiro" (1955) e "Fenómeno da Ingravidad" (1963) não só podem ser oportunos em suscitar questões sobre relatividade, em que temos cenas interessantes a serem discutidas, mas têm a competência de desencadear questionamentos sobre o conhecimento científico. Para refletir sobre tais obras, elaboramos as seguintes questões: O conhecimento científico é absoluto? O que faz ser ou não absoluto? Quais são os fatores para termos uma teoria bem aceita? Pensar em um conhecimento que é aberto para novos estudos e como funciona esse processo, além de percebemos que ele não é formado por verdades absolutas e atemporais. Em outra frente, a última pergunta pode conduzir ao um novo debate que envolva a necessidade das comunidades científicas estarem discutindo o novo estudo Neste momento, podemos também incluir a importância de discutir qualquer pesquisa a partir de sua geografia a fim de entendermos de onde ela é abordada e sua necessidade para tal lugar e tempo (LIVINGSTONE, 2003). Para isso, indicamos apresentação do contexto da virada do século XIX para o século XX em que o espaço e o tempo estão sendo explicitados em diferentes áreas do conhecimento humano como, por exemplos, a área técnica e as artes (GALISON, 2005; HENDERSON, 2008). Desta forma, podemos problematizar a noção de conhecimentos universais ao apresentar sua localidade, em que determinada cultura refrata e reflete discussões que conduzem a novas respostas. 
Levantamos algumas questões que podem ser problematizadas no ensino de ciências. No entanto, enxergamos que há inúmeras possibilidades para outras questões que podem emergir na leitura desses quadros. Assim, entendemos que esse trabalho é um primeiro olhar que está aberto para novas reflexões e implicações.

\section{Considerações finais}

Os passos realizados até aqui nos ajudaram para a construção de uma narrativa em que conseguimos ler alguns quadros da obra de Remedios Varo. A partir da leitura feita, conseguimos enxergar caminhos para questionar e contrapor imagens distorcidas sobre a ciência no ensino. Acreditamos que o esforço em optar por um ensino sobre a ciência nos proporciona o entendimento da ciência como empreendimento dinâmico e cultural.

Ao trazer questões através da leitura das telas conseguimos apontar aspectos importantes para discutir em sala de aula, como: processos de demarcação e encontro de conhecimentos; supervalorização e estereótipos do cientista; relações de controle e domínio sobre a natureza; "neutralidade"; mutabilidade e temporalidade do conhecimento científico. Contudo, como o ensino por questões é aberto, consideramos que há outros aspectos e questões que podem emergir da leitura e conduzir novos debates.

Mesmo não sendo o objetivo deste artigo discutir questões de gênero, ressaltamos que nos quadros os cientistas representados são todos homens. Tal fato pode conduzir novos questionamentos em sala de aula, pois esta apresentação retrata culturas que mulheres não ocupam lugares pertencente a ciência ou quando habitam não são reconhecidas como profissionais da área, ou são poucos os exemplos. O próprio exemplo de Remedios Varo é significativo, pois trazemos a voz de uma mulher do período que foge dos artistas surrealistas, normalmente trabalhados nessa ponte entre ciência e arte, como Salvador Dalí (1904-1989) e René Magritte (1898-1967). Somado a isto, Remedios é um dos poucos exemplos de mulheres que conseguiram acessar o meio científico por meio do seu trabalho temporário de ilustradora científica. Em contrapartida a essa realidade, Remedios oferece em sua obra outras imagens que contrastam as representações analisadas. Em quadros como "Creación de las aves" de 1957 (disponível em: <https://remedios-varo.com/creacion-de-las-aves-1957/>) e "Papilla Estelar" de 1958 (disponível em: <https://remedios-varo.com/papilla-estelar-1958/>) observamos figuras femininas imersas em cenários da ciência que podem ser indícios de uma valorização feminina através da ciência.

Por último, reafirmamos que a intenção de trabalhar com a arte neste artigo é promover discussões para um ensino sobre as ciências, em que os seus processos possam ser constantemente problematizados. Trazemos aqui o projeto de retratar a ciência e a arte como expressões de determinado período e lugar, portanto culturas. Ao produzir tal leitura nos esforçamos em fornecer subsídios para suscitar questões junto aos estudantes e possam, posteriormente, causar incomodo ao escutarem discursos autoritários que utilizam da ciência como mecanismos de exploração social e ambiental. De outra forma, enxergamos a potencialidade 
deste olhar ao aproximar o aluno da ciência, ao encará-la de forma mais humana e desvinculada da ideia de conhecimento dogmático através da conexão feita entre ciência e arte por meio de uma abordagem cultural.

\section{Referências}

ANDRADE, R. R. D; NASCIMENTO, R. S; GERMANO, M. G. Influência da Física Moderna na obra de Salvador Dalí. Caderno Brasileiro de Ensino de Física, v. 24, n. 3, p. 400423, 2007.

BAKER, E.; ORESKES, N. It's No Game: Post-Truth and the Obligations of Science Studies. Social Epistemology Review and Reply Collective, v. 6, n. 8, p. 1-10, 2017.

BRETON, A. Manifesto do Surrealismo. Disponível em: <http://www.culturabrasil.org/ breton.htm>. Acesso em: 01 out. 2019.

CALVO, A. L. Remedios Varo: El espacio y el exilio. Alicante: Coleção LILITH, 2009.

CLOUGH, M. P. Teaching the nature of science to secondary and post-secondary students: questions rather than tenets. Disponível em: $<$ http://pantaneto.co.uk/teaching-the-nature-ofscience-to-secondary-and-post-secondary-students-questions-rather-than-tenets-michaelclough/>. Acesso em: 12 out. 2019.

CHANSIGAUD, V. Scientific Illustrators. In: LIGHTMAN, B. (Ed.). A Companion to the History of Science. Nova Jersey: Wiley Brackwell 2016. p. 111-125.

CRUZ, F. F. S. Mecânica Quântica e a cultura em dois mundos. In: FREIRE JR, O; PESSOA JR, O; BROMBERG, J. L. (org.). Teoria quântica: estudos históricos e implicações culturais. São Paulo: Livraria da Física, 2011, p. 303-320.

FERNANDES, R. F. A. N.; PIRES, F. F.; FORATO, T. C.; SILVA, J. A. Pinturas de Salvador Dalí para introduzir conceitos de Mecânica Quântica no Ensino Médio. Caderno Brasileiro de Ensino de Física, v. 34, n. 2, p. 509-529, 2017.

FORATO, T. C. M.; PIETROCOLA, M.; MARTINS, R. A. Historiografia e natureza da ciência na sala de aula. Caderno Brasileiro de Ensino de Física, v. 28, n. 1, p. 27-59, 2011.

FRIEDMAN, A. J. Explaining the Universe: Why Arts Education and Science Education Need Each Other. American Art, v. 11, n. 3, p. 2-7, 1997. 
GALISON, P. Os relógios de Einstein: o lugar do tempo. Ciência e Ambiente, p. 8-34, 2005.

GALILI, I. On the Power of Fine Arts Pictorial Imagery in Science Education. Science \& Education, n. 22, p. 1911-1938, 2013.

GIL-PÉREZ, D.; MONTORO, I. F.; ALÍS, J. C.; CACHAPUZ, A.; PRAIA, J. Para uma imagem não deformada do trabalho científico. Ciência \& Educação, v. 7, n. 2, p. 125-153, 2001.

GEERTZ, C. As interpretações das culturas. Rio de Janeiro: Guanabara, 1989.

GUERRA, A; BRAGA, M; REIS, J. C. Tempo, espaço e simultaneidade: Uma questão para os cientistas, artistas, engenheiros e matemáticos no século XIX. Caderno Brasileiro de Ensino de Física, v. 27, n. 3, p. 568-583, Florianópolis, 2010.

HENDERSON, L. D. Einstein and 20TH- Century Art: A romance of many Dimensions. In: GALISON, P. L; HOLTON, G; SCHWEBER, S. S. (Ed.). Einstein for the twenty-first century: His legacy in science, art, and modern culture. London: Princeton University Press, 2008. p. 101-129.

HOBSBAWN, E. J. A era dos extremos: o breve século XX. São Paulo: Companhia das Letras, 1994. $478 \mathrm{p}$.

HODSON, D. Science education as a call to action. Canadian Journal of Science, Mathematics and Technology Education, v. 10, n. 3, p. 197-206, 2010.

IRZIK, G.; NOLA, R. A family resemblance approach to the nature of science for science education. Science \&Education, v. 20, n. 7-8, p. 591-607, 2011.

JONES, C. A. Rendering Time. In: GALISON, P. L; HOLTON, G; SCHWEBER, S. S. (Ed.). Einstein for the twenty-first century: his legacy in science, art, and modern culture. London: Princeton University Press, 2008. p. 130-149.

JOSEPHSON, P. Big Science e Tecnologia no século XX. Fronteiras: Revista Catarinense de História, n. 27, p. 149-168, 2018.

KAPLAN, J. A. Viajes Inesperados: EI arte y la vida de Remedios Varo. Madrid: Fundación Banco Exterior, 1988. 
KAPLAN, J. A. Remedios Varo: Voyages and Visions. Woman's Art Journal, v. 1, n. 2, p. 13-18, 1980.

KAPLAN, L.A. Traces of Influence: Giorgio de Chirico, Remedios Varo, and "lo Real Maravilloso". The Latin Americanist, v. 54, n. 3, p. 25-51, 2010.

LIVINGSTONE, D. Putting Science in its place - Geographies of Scientific Knowledge. Chicago: The University of Chicago Press, 2003.

MARTINS, A. F. P. Natureza da Ciência no ensino de ciências: uma proposta baseada em “temas" e "questões". Caderno Brasileiro de Ensino de Física, v. 32, n. 3, p. 703-737, 2015.

McCOMAS, W. F.; ALMAZROA, H.; CLOUGH, M. The Nature of Science in Science Education: an introduction. Science \&Education, v. 7, n. 6, p. 11-532, 1998.

MOURA, B.A. O que é natureza da Ciência e qual sua relação com a História e Filosofia da Ciência? Revista Brasileira de História da Ciência, v. 7, n. 1, p. 32-46, 2014.

MOURA, C. B; GUERRA, A. História cultural da ciência: um caminho possível para a discussão sobre as práticas científicas no ensino de ciências? Revista Brasileira de Pesquisa em Educação em Ciências, v. 16, n. 3, p. 725-748, 2016.

NUMMEDAL, T. The Alchemist In: LIGHTMAN, B. (Ed.). A Companion to the History of Science. Nova Jersey: Wiley Brackwell, 2016. p. 58-70.

ORTIZ, M. M. Alquímicamente surrealista: la pintura de Remedios Varo. La manzana de la discordia, v. 6, n. 2, p. 85-94, 2011.

OSBORNE, J; COLLINS, S.; RATCLIFFE, M.; MILLAR, R.; DUSCHL, R. What "ideasabout-science" should be taught in school science? A Delphi study of the expert community. Journal of research in science teaching, v. 40, n. 7, p. 692-720, 2003.

OSTROWER, F. Criatividade e Processos de Criação. 12. ed. Petrópolis: VOZES,1997. $187 \mathrm{p}$.

OSTROWER, F. A sensibilidade do intelecto: Visões paralelas de espaço e tempo na arte e na ciência. 5. ed. Rio de Janeiro: Campus,1998. 305 p. 
PRAIA, J.; GIL-PÉREZ, D.; VILCHES, A. O papel da Natureza da Ciência na educação para cidadania. Ciência \& Educação, v. 13, n. 2, p. 141-156, 2007.

PIMENTEL, J. La Revolucíon Científica. In: ARTOLA, M.(dir.). História de Europa: Tomo II. Madrid: Espasa Calpe, 2007. p. 163-238.

REIS, J. C.; GUERRA, A.; BRAGA, M. Ciência e arte: relações improváveis. História, Ciências, Saúde - Manguinhos, v. 13, p. 71-87, 2006.

REIS, U.V. Os conceitos de espaço e tempo no ensino médio de física: uma possibilidade de atuação em sala de aula. 2015. 195 f. Dissertação (Mestrado em Ciência, Tecnologia e Educação) - Centro Federal de Educação Tecnológica Celso Suckow da Fonseca, Rio de Janeiro.

RIES, O. El exilio y la política nacionalista mexicana Remedios Varo, Leonora Carrington y el nacionalismo mexicano. Revista Izquierdas, n. 8, p. 1-20, 2010.

RUDOLPH, J. L.; HORIBE, S. What do we mean by science education for civic engagement? Journal of Research on Science Teaching, v. 53, n. 6, p. 805-820, 2016.

SANTOS, B. S. Um discurso sobre as ciências. 5. ed. São Paulo: Cortez, 2008.

SOUSA, F.S. Um cigarro para um amigo: a Guerra Civil Espanhola na Imprensa Comunista Mexicana. Outros Tempos, v. 13, n. 21, p. 222-245. 2016.

VASCONCELLOS, C.M. As Representações das Lutas de Independência no México na ótima do Muralismo: Diego Rivera e Juan O’ Gorman. Revista de História, v. 152, n. 1, p. 283-304, 2005.

VARO, R. Letters, dreams \& other writings. Translated by: Margaret Carson. 1. ed. New York: Wakefield Press, 2018.

VIDEIRA, A. A. P. Historiografia e história da ciência. Escritos (Fundação Casa de Rui Barbosa), Rio de Janeiro, v. 1, p. 111-158, 2007.

ZANETIC, J. Física também é cultura. 1989. Tese (Doutorado em Educação) - Faculdade de Educação, Universidade de São Paulo, São Paulo.

ZANETIC, J. Física e Arte: uma ponte entre duas culturas. Pro-Posições, v. 17, n. 1, 2006.

(cc) BY-NC-ND Direito autoral e licença de uso: Este artigo está licenciado sob uma Licença Creative Commons. 